\title{
Emissão/abscisão de estruturas reprodutivas do algodoeiro herbáceo, cv. CNPA 7H: efeito do estresse hídrico ${ }^{1}$
}

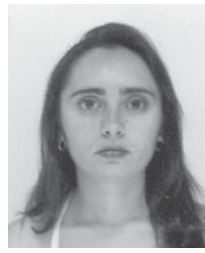

Francineuma P. de Arruda ${ }^{2}$, Alberício P. de Andrade ${ }^{3}$, Ivandro de F. da Silva ${ }^{3}$, Ivonete E. Pereira ${ }^{4} \&$ Mário A. M. Guimarães ${ }^{4}$

\footnotetext{
1 Parte da Dissertação de Mestrado apresentada pela primeira autora ao Curso de Pós-Graduação em Manejo de Solo e Água do CCA/UFPB, Campus III, Areia, PB.

2 CCA/UFPB. Campus III, Areia, PB. CEP 58 397-000. Fone: (83) 9969-2411. E-mail: n_arruda@bol.com.br (Foto)

${ }^{3}$ DSER/CCA/UFPB. Campus III, Areia, PB. Fone (83) 362-2300

${ }^{4}$ Graduando, CCA/UFPB
}

Protocolo $038-29 / 3 / 2001$

\begin{abstract}
Resumo: O presente estudo foi conduzido no período de julho a dezembro de 1998, em galpão coberto, no DSER/CCA/UFPB, município de Areia, PB, com o objetivo de se avaliar o efeito dos níveis de água disponível no solo (AD) (20, 40,60 e 80\%) sobre a emissão/abscisão de estruturas reprodutivas do algodoeiro herbáceo, cv. CNPA 7H; utilizou-se delineamento experimental inteiramente casualizado, com quatro tratamentos e três repetições, em três épocas de amostragem. $\mathrm{O}$ crescimento vegetativo e o reprodutivo, aumentaram com os níveis de AD no solo, sendo a menor média de altura de plantas $(34,5 \mathrm{~cm})$, área foliar $\left(633,05 \mathrm{~cm}^{2}\right)$, acumulação de fitomassa da parte aérea $(9,04 \mathrm{~g})$, botões florais $(4,67)$, flores $(3,50)$, maçãs $(2,33)$ e capulhos $(1,33)$ por planta, observada no tratamento com o nível de $20 \%$ da $A D$ e a maior, $74,33 \mathrm{~cm}$, $2.634,81 \mathrm{~cm}^{2}, 24,86 \mathrm{~g}, 9,67,7,0,6,0$ e 4,3 por planta, respectivamente, no tratamento com o nível de $60 \%$ da AD. Apesar do estresse hídrico ter afetado $(p<0,05)$ quantitativamente o aumento da emissão e abscisão de estruturas reprodutivas do algodoeiro, existe uma interdependência entre essas estruturas, independente do nível de estresse hídrico a que foi submetido; assim, o aumento ou redução do número de botões florais retidos culmina com o de flores, maçãs e capulhos de forma sucessiva, mantendo uma proporcionalidade padrão.
\end{abstract}

Palavras-chave: Gossypium hirsutum, manejo de água, crescimento, botões florais

\section{Emission/abscission of reproductive structures of herbaceous cotton, cv. CNPA 7H: Effect of the water stress}

\begin{abstract}
The present study was conducted from July to December 1998, in a covered area at DSER/CCA/UFPB, Areia/PB with the objective of evaluating the effect of four levels of available water (AW - 20,40, 60 and $80 \%$ ) in soil on the emission/abscission of reproductive structures of herbaceous cotton plant, cv. CNPA 7H. A completely randomized experimental design was used, with four treatments replicated three times and sampled at three different dates. Vegetative and reproductive growth increased with AW levels in soil. Minimum mean values for plant height $(34.5 \mathrm{~cm})$, leaf area $\left(633.05 \mathrm{~cm}^{2}\right)$, biomass accumulation of aerial parts $(9.04 \mathrm{~g})$, number of flower buds (4.67), flowers (3.50), fruits (2.33) and bolls (1.33) per plant, were observed for the $20 \%$ AW treatment. In contrast, the highest mean values observed for the $60 \%$ AW treatment, respectively, were $74.33 \mathrm{~cm}, 2,634.8 \mathrm{~cm}^{2}, 24.86 \mathrm{~g}, 9.67,7.0,6.0$ and 4.3 . Water stress showed significant effect $(p<0,05)$ on emission and abscission of reproductive structures of cotton plants in an independent way. Thus, an increase or a decrease in the number of retained flower buds precedes a similar pattern for the number of flowers, fruit and mature bolls, keeping a standard proportionality, regardless of the water stress level.
\end{abstract}

Key words: Gossypium hirsutum, water management, growth, flower buds

\section{INTRODUÇÃO}

A produção de algodão é uma função complexa, que depende de fatores vinculados à dinâmica de produção e retenção de estruturas reprodutivas. Segundo Hearn (1980) e Jackson \& Arkin (1982) o algodoeiro tem padrão de crescimento indeterminado, caracterizado por um aumento exponencial do número de folhas e estruturas reprodutivas, em função do tempo. Afirmam, ainda, que essas estruturas competem por assimilados disponíveis na planta. Como resultado desta competição, ocorre redução no crescimento vegetativo e na produção de botões florais (Guinn, 1979; Mauney, 1979). Uma 
parte das estruturas reprodutivas cai na fase de botão floral ou como maçã jovem, inclusive em condições ótimas de crescimento (Orgaz et al., 1991). Para Rosolem (1999) a abscisão de estruturas reprodutivas é regulada pelo balanço entre açúcares no tecido e o teor de etileno. Segundo Lima (2001) situações de deficiência hídrica e estresse osmótico, provocam aumento tanto de etileno quanto de ácido abscísico - hormônios que participam dos processos de amadurecimento e envelhecimento, como queda de folhas e frutos. Para esse autor, a relação entre estresse e metabolismo hormonal não é bem conhecida. Reconhece-se, entretanto, que plantas submetidas a estresse mostram sintomas de envelhecimento precoce.

McMichael et al. (1973), Orgaz et al. (1991) e Oosterhuis (1992) afirmam que o ambiente pode aumentar tanto a abscisão foliar quanto a de frutos. Dos fatores ambientais que podem provocar a abscisão no algodoeiro, a deficiência hídrica no solo tem sido considerada um dos principais, justamente quando esta causa acentuado estresse às plantas. A disponibilidade de água no solo afeta os processos fisiológicos das plantas e, conseqüentemente, o crescimento e o desenvolvimento (Doorenbos \& Kassam, 1994; Nápoles et al., 1999) através dos efeitos sobre o estado de água na planta, fotossíntese e expansão foliar (Wright \& Nageswara Rao, 1994).

O estresse hídrico em determinadas fases fenológicas, pode comprometer o rendimento e a qualidade do produto (Nápoles et al., 1999) e promover a queda de botões florais e maçãs jovens (McMichael et al., 1973; Guinn \& Mauney, 1984a, b). Comumente, acredita-se que a floração/frutificação é o período mais sensível ao estresse hídrico (Millar, 1976; Espínola Sobrinho \& Maia Neto, 1992; Luz et al., 1997); todavia, existe certa controvérsia a respeito do efeito da deficiência hídrica sobre a queda de estruturas reprodutivas, encontrando-se respostas diferentes em função de sua duração e severidade, assim como da fase de desenvolvimento na qual se encontra o cultivo, ao se aplicar o estresse. Pesquisadores (McMichael et al., 1973; Guinn \& Mauney, 1984a e b) têm verificado que o estresse hídrico reduz tanto a produção de flores como a retenção de maçãs, mas outros autores observaram aumento na produção de flores, quando o cultivo foi submetido ao estresse hídrico (Kittock, 1979) o que pode estar associado, percentualmente, à menor queda de botões florais nos tratamentos com déficit de água que nos tratamentos bem irrigados (Radulovich, citado por Orgaz et al., 1991).

Sabe-se que a redução ou o aumento da abscisão de estruturas reprodutivas do algodoeiro está, também, associada ao estresse hídrico, porém a dinâmica da relação que envolve a taxa de emissão/abscisão entre essas estruturas não é, ainda, bem conhecida. Considerando-se esses aspectos, o trabalho teve como objetivo avaliar o efeito de diferentes níveis de água disponível no solo sobre a interdependência entre as estruturas reprodutivas (botões, flores, maçãs e capulhos) do algodoeiro herbáceo, cv. CNPA 7H.

\section{MATERIAL E MÉTODOS}

O trabalho foi conduzido de julho a dezembro de 1998, em um galpão telado coberto com telhas transparentes de fibra de vidro, do Departamento de Solos e Engenharia Rural do Centro de Ciências Agrárias da Universidade Federal da Paraíba (CCA/ UFPB) no município de Areia, PB. O local do ensaio dista aproximadamente $2 \mathrm{~km}$ ao Norte do ponto das coordenadas $6^{\circ} 58^{\prime}$ da latitude Sul, $35^{\circ} 41^{\prime}$ de longitude a Oeste de Greenwich e 575 m de altitude. Segundo a classificação de Köppen o clima da região é do tipo As', ou seja, quente e úmido, com chuvas de outono-inverno e período de estiagem de 5 a 6 meses.

A cultura foi semeada em um material do solo franco-argiloarenoso, classificado como Latossolo Vermelho-Amarelo (Nóbrega, 1996) proveniente de uma área experimental do Centro de Ciências Agrárias - UFPB, situada na microrregião do Brejo Paraibano, município de Areia. As determinações físicas e químicas dos $20 \mathrm{~cm}$ superficiais do perfil (Tabela 1) constaram de granulometria, determinada pelo método hidrômetro (Day, 1965); densidade do solo e de partículas, pelos métodos do torrão parafinado e da proveta, de acordo com Blake (1965a, b) respectivamente; conteúdo de água no solo a 0,01 e a 1,5 $\mathrm{MPa}$, seguindo metodologia proposta por Forsythe (1975); $\mathrm{pH}\left(\mathrm{H}_{2} 0\right)$, $\mathrm{Ca}^{++}+\mathrm{Mg}^{++}, \mathrm{K}^{+}, \mathrm{Al}^{+++}, \mathrm{P}$ e condutividade elétrica, de acordo com Tedesco et al. (1985) e matéria orgânica pela metodologia de Raij et al. (1979).

De acordo com os resultados da análise química do solo, procedeu-se à adubação corretiva e de manutenção com NPK (60-60-90 $\mathrm{kg} \mathrm{ha}^{-1}$ ) seguindo-se recomendações do Laboratório de Química e Fertilidade de Solo do CCA-UFPB, a qual consistiu da aplicação, em cada vaso, de $2,6 \mathrm{~g}$ de $\mathrm{P}_{2} 0_{5}$ na forma de superfosfato simples, $0,58 \mathrm{~g}$ de $\mathrm{KCl}$ (cloreto de potássio) e 1,74 g de sulfato de amônio, sendo o $\mathrm{N}$ parcelado em duas aplicações, $0,58 \mathrm{~g}$ na adubação de fundação, juntamente com o $\mathrm{P}$ e o $\mathrm{K}$, e 1,16 g em cobertura, $34 \mathrm{~d}$ após o plantio. Além de NPK, todos os tratamentos receberam, uniformemente, uma adubação complementar com óxido de magnésio (4,62 g por vaso) com base nos sintomas de deficiência de $\mathrm{Mg}$, apresentado pelas plantas, após a formação dos frutos (maçãs).

Os tratamentos foram definidos por quatro níveis de água disponível no solo (AD): 80, 60, 40 e 20\% da AD. Para evitar condições de estresse hídrico e garantir o crescimento uniforme das plântulas, do plantio até a indução dos tratamentos $(24 \mathrm{~d}$ após a emergência) todas as plantas foram irrigadas diariamente, com reposição da água consumida, até atingir o nível de $80 \%$ da AD. Após a indução do estresse hídrico, o conteúdo de água no solo foi controlado diariamente, às 13:00 h, pelo peso do conjunto vaso + solo + água + planta, repondo-se o volume de água consumida (evapotranspirada) segundo o tratamento preestabelecido. Nesse ensaio que faz parte de uma série de três, adotou-se o delineamento experimental inteiramente casualizado, com quatro tratamentos e três repetições, em três

Tabela 1. Características físicas e químicas das amostras de solo coletadas na Fazenda Chã do Jardim. Areia, PB

\begin{tabular}{|c|c|c|c|c|c|c|c|c|c|c|c|c|c|}
\hline \multicolumn{3}{|c|}{ Textura } & \multicolumn{2}{|c|}{ Densidade } & \multicolumn{2}{|c|}{$\mathrm{CAS}^{*}$} & \multirow{3}{*}{$\begin{array}{c}\mathrm{pH} \\
\mathrm{H}_{2} 0\end{array}$} & \multirow[b]{2}{*}{$P$} & \multirow{2}{*}{$\mathrm{K}$} & \multirow{2}{*}{$\mathrm{Al}^{3+}$} & \multirow{2}{*}{$\mathrm{Ca}^{2+}+\mathrm{Mg}^{2+}$} & \multirow{3}{*}{$\begin{array}{l}\text { M.O. } \\
\mathrm{g} \mathrm{dm}^{-3}\end{array}$} & \multirow{2}{*}{$C E^{*}$} \\
\hline Areia & Silte & Argila & Solo & Partículas & $0,01 \mathrm{MPa}$ & $1,5 \mathrm{MPa}$ & & & & & & & \\
\hline \multicolumn{3}{|c|}{$\mathrm{g} \mathrm{kg}^{-1}$} & \multicolumn{2}{|c|}{$\mathrm{kg} \mathrm{dm}^{-3}$} & \multicolumn{2}{|c|}{$\mathrm{g} \mathrm{kg}^{-1}$} & & \multicolumn{2}{|c|}{$\mathrm{mg} \mathrm{dm}^{-3}$} & \multicolumn{2}{|c|}{$\mathrm{cmol}_{\mathrm{c}} \mathrm{dm}^{-3}$} & & $\mathrm{dS} \mathrm{m} \mathrm{m}^{-1}$ \\
\hline 569 & 77 & 354 & 1,02 & 2,63 & 244,8 & 136,0 & 5,5 & 1,8 & 17,0 & 0,29 & 4,5 & 32,8 & 0,14 \\
\hline
\end{tabular}


épocas de amostragem, totalizando 36 parcelas. A unidade experimental foi representada por um vaso plástico com capacidade para $20 \mathrm{~L}$, contendo $15 \mathrm{~kg}$ de material de solo seco a estufa (TFSE). A cultura utilizada foi o algodoeiro herbáceo (Gossypium hirsutum L. r. latifolium Hutch) cultivar CNPA 7H, procedente do Centro Nacional de Pesquisa do Algodão CNPA/EMBRAPA, Campina Grande, PB.

Para estudo e interpretação dos resultados, determinou-se crescimento vegetativo, através da determinação dos dados de área foliar (AF) semanal, utilizando-se a equação $\mathrm{AF}=\mathrm{K} \times \mathrm{L} \times \mathrm{C}$, em que: $\mathrm{L}$, a largura da folha; $\mathrm{C}$, o comprimento da folha, e K, o coeficiente de correção de valor 0,67 , recomendado por Diniz (1996); altura de plantas (AP), a cada 7 d, e acumulação de fitomassa da parte aérea (FA) e crescimento reprodutivo, realizando-se diariamente a contagem de botões florais, flores, maçãs e capulhos, a partir da fase dos primeiros botões até a última semana de abertura dos frutos, sendo expressos em termos de número de estrutura reprodutiva por planta. Os resultados foram submetidos à análise de variância e as médias comparadas pelo teste de Tukey a 5\% de probabilidade (Gomes, 1985); aplicou-se a análise de regressão para as variáveis que apresentaram efeito significativo (Steel \& Torrie, 1980).

\section{RESULTADOS E DISCUSSÃO}

\section{Crescimento vegetativo}

Observa-se, na Figura 1, evolução da área foliar (A), altura de plantas (B) e acumulação da fitomassa da parte aérea (C) do algodoeiro e efeito dos diferentes níveis de $\mathrm{AD}$ sobre essas variáveis (D, E e F). Constatou-se que, $40 \mathrm{~d}$ após do plantio (DAP) aproximadamente, tanto a AF, AP quanto a FA, aumentaram com os teores de água no solo $(\mathrm{A}, \mathrm{B}$ e C $)$ chegando a apresentar efeito altamente significativo $(p<0,01)$ entre os tratamentos para $\mathrm{AP}$ e $\mathrm{AF}$, aos $100 \mathrm{DAP}$, quando as plantas atingiram o crescimento máximo e, para FA, no final do ciclo da cultura (D, E e F). Salienta-se que dos 40 aos 100 DAP não houve diferença $(p>0,05)$ entre essas variáveis em relação aos tratamentos de 80,60 e $40 \%$ da $\mathrm{AD}$, porém esses, a partir dos 45 DAP, começaram a apresentar superioridade nesses parâmetros em relação ao de $20 \%$ da AD no solo. Resultados semelhantes foram encontrados por Souza et al. (1999). A redução da AF, AP e FA da cultura, é uma contingência da limitação da água no solo, conforme retratado por Hsiao (1973) para crescimento de plantas.

De acordo com as equações obtidas na análise de regressão polinomial dos dados de AP, AF e FA (Fig. 1) observou-se que o algodoeiro atingiu o seu potencial máximo de crescimento vegetativo (D, E e F) com o nível de $\mathrm{AD}$ em torno de $60 \%$, havendo redução de $5,4 \%$ na $\mathrm{AP}, 18,5 \%$ na $\mathrm{AF}$ e de $25,0 \%$ na $\mathrm{FA}$, quando se aumentou o nível de água disponível no solo, para $80 \%$ da AD. Pereira et al. (1997) analisando o fator conteúdo de água no solo, isoladamente, observaram que o maior consumo de água pelas plantas, nos níveis mais altos de água disponível, não resultou em maior crescimento ou desenvolvimento, reforçando a dedução de que a disponibilidade de água do solo para crescimento, deve ser menor que

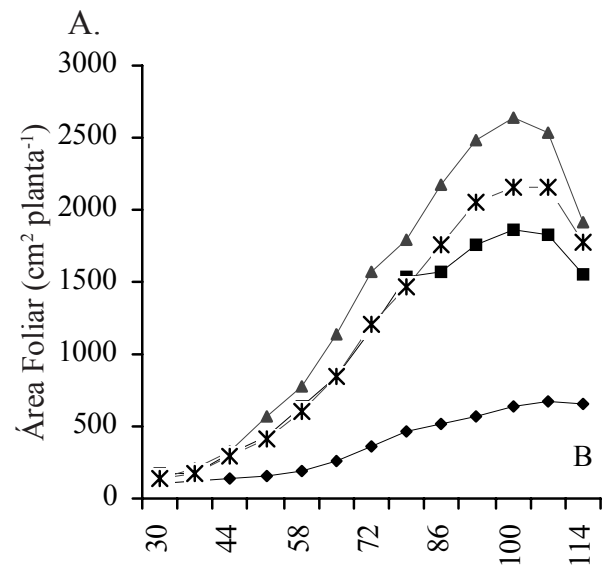

D.

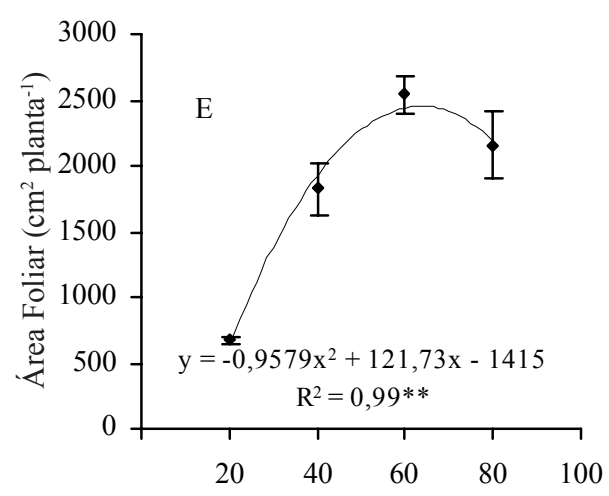

B.

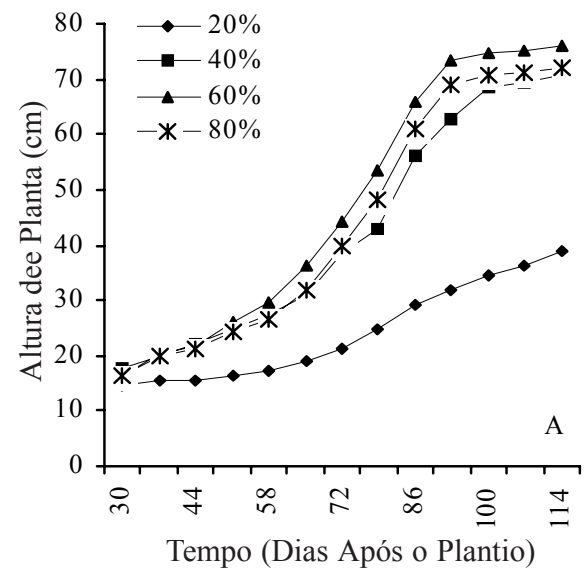

E.

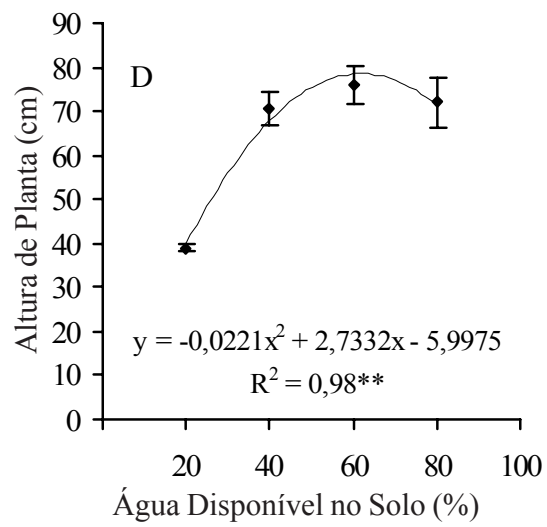

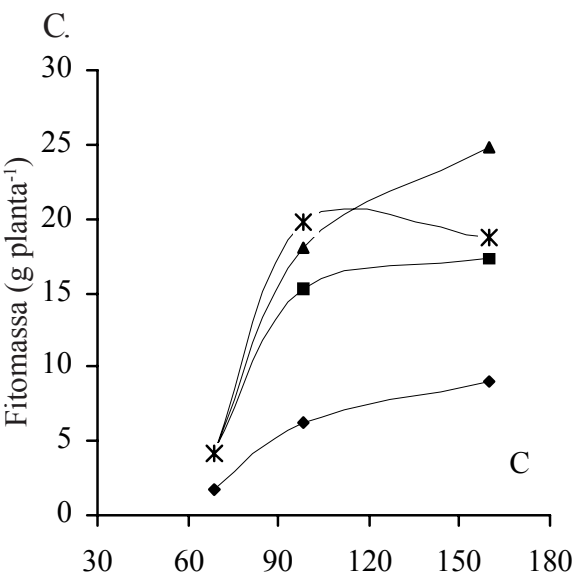

F.

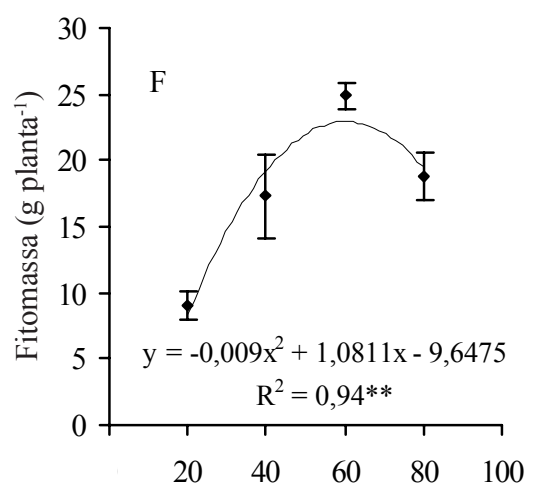

Figura 1. Evolução da área foliar (A), altura de plantas (B) e fitomassa da parte aérea (C) do algodoeiro herbáceo, cv. CNPA 7H e efeito do nível de água disponível no solo (20,40, 60 e 80\%) sobre esses parâmetros (D, E e F) 
$80 \%$ da AD pois, segundo Souza \& Beltrão (1997) o excesso de água influencia a deficiência total ou parcial de oxigênio no solo, podendo causar efeitos no metabolismo e, dependendo do estádio da cultura e duração do encharcamento, afetar o rendimento.

\section{Crescimento reprodutivo}

A evolução do crescimento reprodutivo do algodoeiro pode ser observada na Figura 2. Constatou-se que o número de estruturas reprodutivas (botões, flores, maçãs e capulhos) aumentou, em geral, com os níveis de água disponível no solo, porém a menor quantidade de estruturas reprodutivas por planta foi observada no tratamento com $20 \%$ da $\mathrm{AD}$ e a maior quantidade no tratamento com o nível de $60 \%$ da AD. Este resultado reforça a afirmação de que no algodoeiro herbáceo, apesar de ser uma cultura relativamente tolerante à seca, seu rendimento pode ser sensivelmente reduzido quando ocorre deficiência de água no solo (Millar, 1976) e que valores acima de $60 \%$ da $\mathrm{AD}$ não proporcionam aumento significativo em termos de crescimento, desenvolvimento ou produção do algodoeiro (Pereira et al., 1997).

Da mesma forma que para crescimento vegetativo observa-se, através das equações obtidas na análise de regressão polinomial dos dados de emissão de estruturas reprodutivas (Fig. 3) que as plantas apresentaram o número máximo de botões $(9,7)$, flores $(7,0)$, maçãs $(6,0)$ e capulhos $(4,3)$ por planta, com o nível de $\mathrm{AD}$ de $60 \%$, ocorrendo redução em volta de $20 \%$ das estruturas reprodutivas, quando o nível de AD foi elevado para $80 \%$ ou reduzido para $40 \%$. Tal resultado sugere que a emissão de estruturas reprodutivas do algodoeiro é sensível à irrigação, podendo diminuir com a falta ou excesso de água no solo, conforme afirmam Grimes et al. (1978).

\section{Correlações entre estruturas reprodutivas do algodoeiro}

A correlação entre estruturas reprodutivas do algodoeiro herbáceo em função dos diferentes níveis de água disponível no solo (Fig. 4) foi do tipo linear. O coeficiente de determinação linear $\left(\mathrm{R}^{2}\right)$ variou entre 0,90 (botões $\mathrm{x}$ flores planta ${ }^{-1}$ e flores $\mathrm{x}$ maçãs planta ${ }^{-1}$ ), e 0,98 (flores x capulhos planta ${ }^{-1}$ ).

Os resultados sugerem que as estruturas reprodutivas do algodoeiro herbáceo são dependentes entre si, independentemente do nível de $\mathrm{AD}$ no solo, e que o número de flores, maçãs e capulhos, aumenta linearmente, em função do número de botões florais planta ${ }^{-1} \mathrm{e}$, assim, sucessivamente. Por outro lado, a equação do tipo linear sugere que o emprego de um sistema de cultivo do algodoeiro, com um suprimento adequado de água no solo, favorece maior aumento na quantidade de botões florais por planta, culminando com o aumento do número de maçãs e,
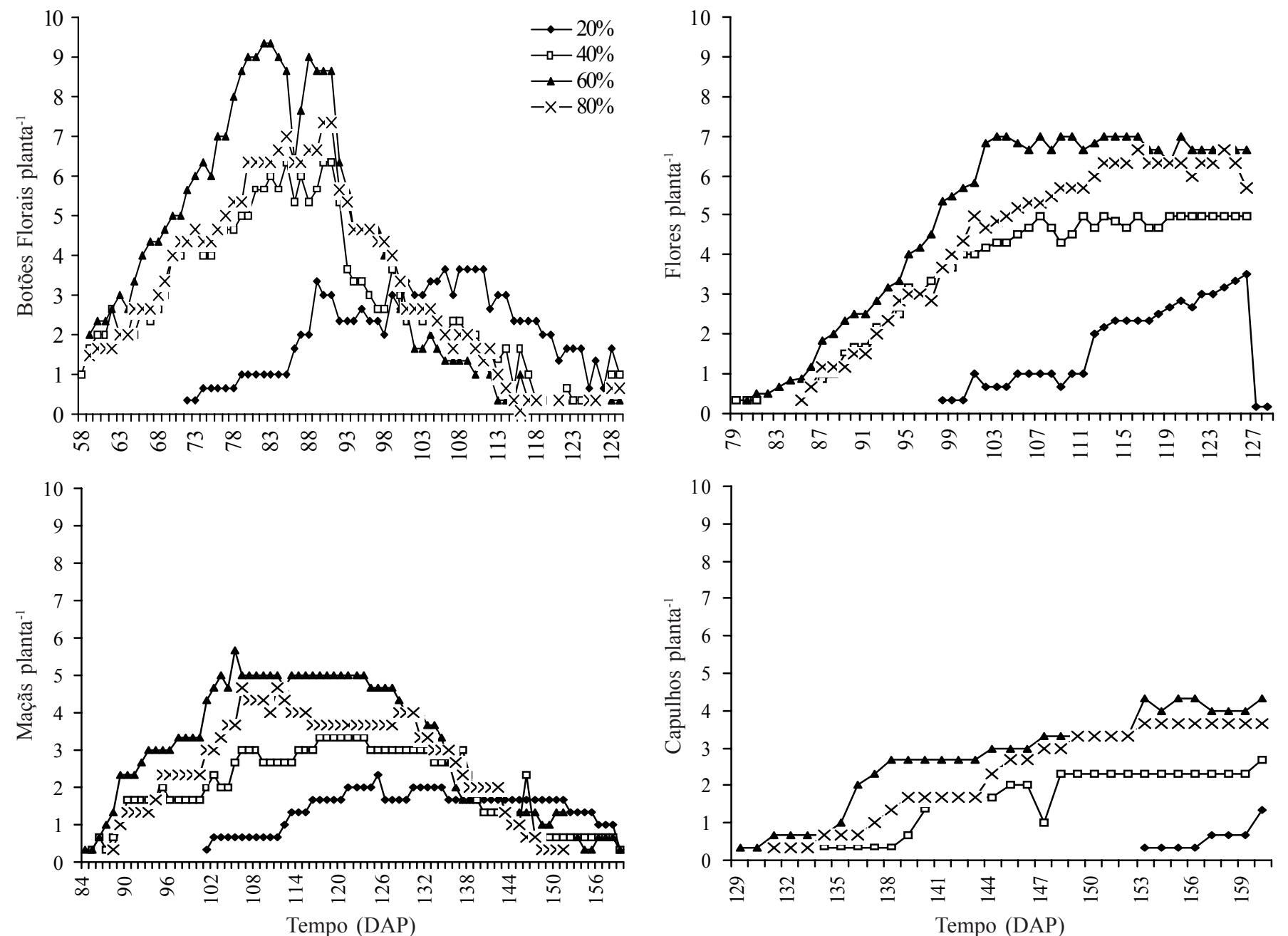

Figura 2. Evolução de estruturas reprodutivas do algodoeiro herbáceo, cv. CNPA 7H, em condições de estresse hídrico provocado a partir da irrigação com 4 níveis de água disponível no solo (20, 40, 60 e 80\%) 

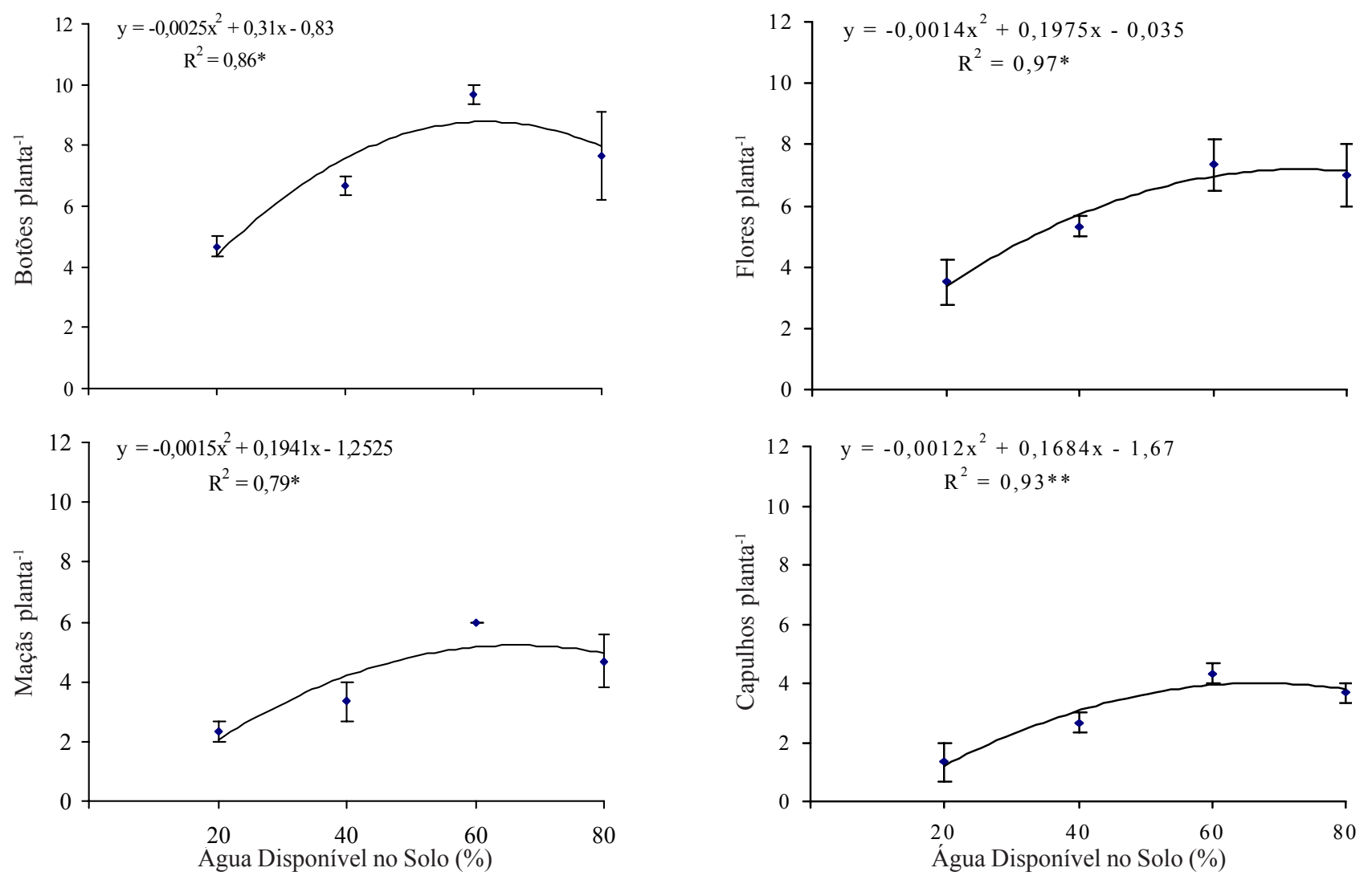

As barras verticais indicam o desvio padrão da média

Figura 3. Efeito do nível de água disponível no solo (20, 40, 60 e 80\%) sobre a emissão de estruturas reprodutivas do algodoeiro herbáceo, cv. CNPA $7 \mathrm{H}$
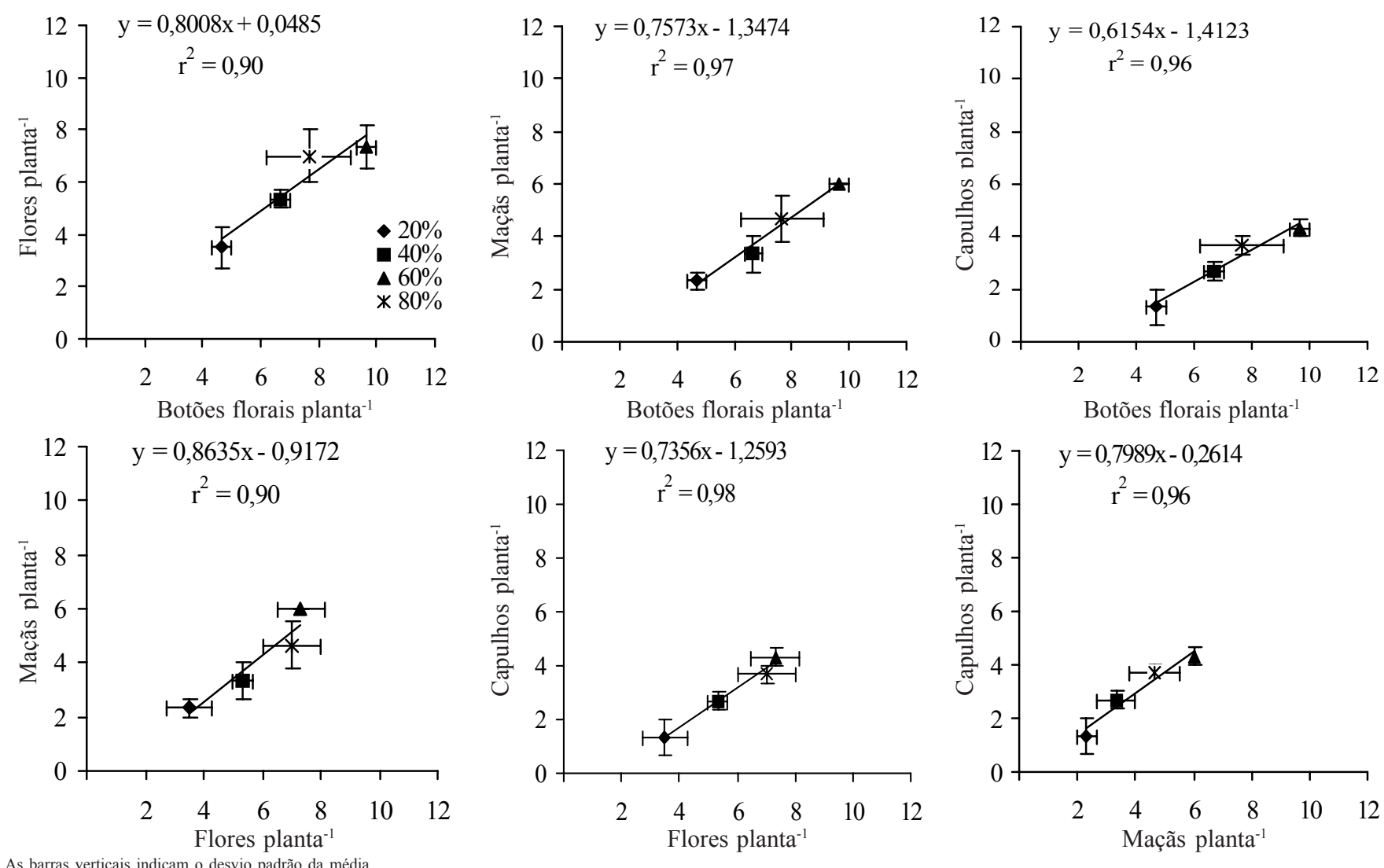

Figura 4. Relação entre estruturas reprodutivas do algodoeiro herbáceo, cv. CNPA 7H, em condições de estresse hídrico, provocado a partir da irrigação com 4 níveis de água disponível no solo (20, 40, 60 e 80\%) 

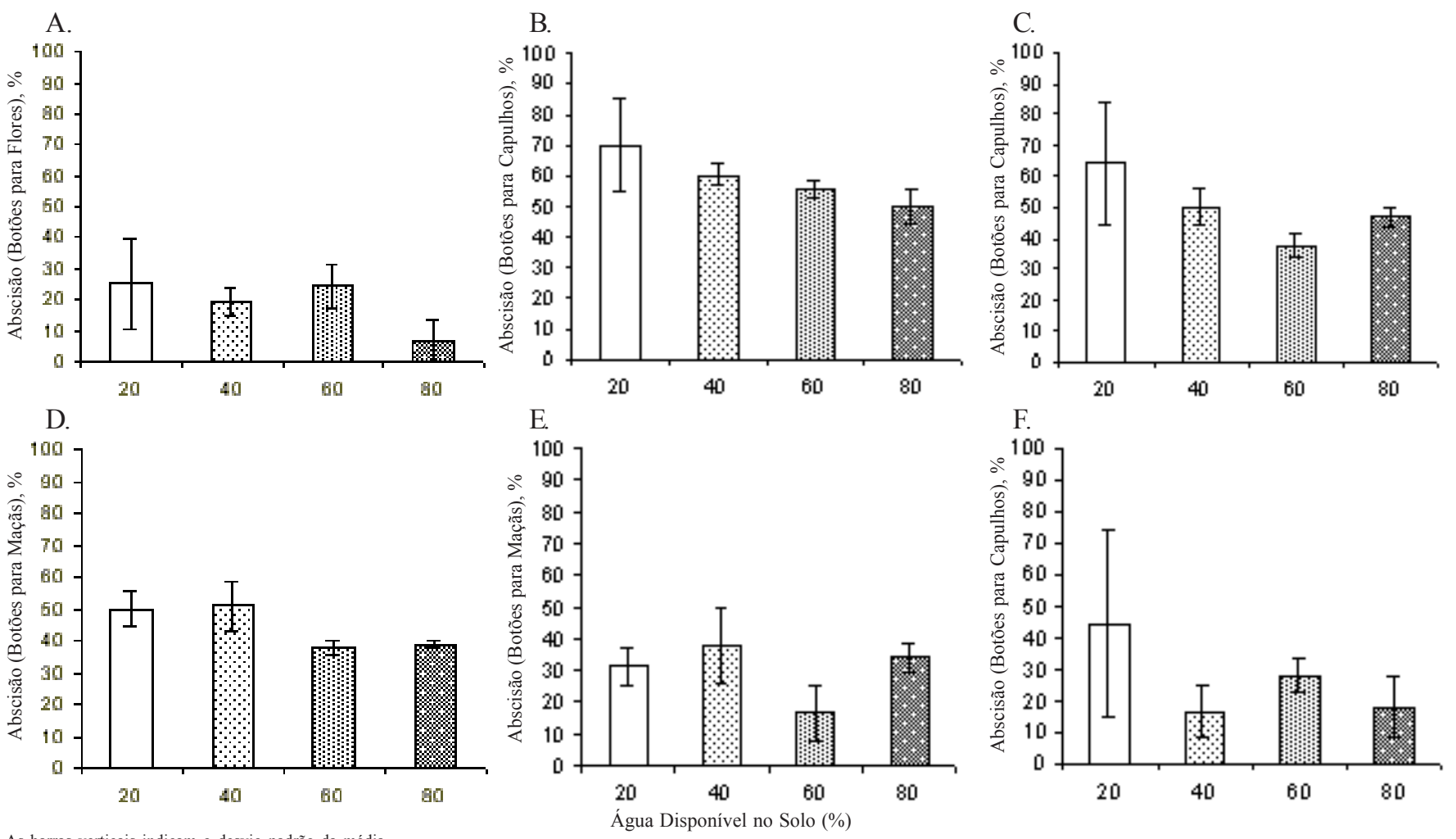

As barras verticais indicam o desvio padrão da média

Figura 5. Efeito do nível de água disponível no solo (20, 40, 60 e 80\%) sobre a abscisão de estruturas reprodutivas do algodoeiro herbáceo, cv. CNPA $7 \mathrm{H}$

conseqüentemente, número de capulhos por planta. Por exemplo, como o nível de $60 \%$ da AD proporcionou maior quantidade no número de botões florais por planta (Fig. 3) justifica-se o aumento no número de flores, maçãs e capulhos do algodoeiro observados nesse nível de AD no solo. McMichael et al. (1973) e Orgaz et al. (1992) afirmam que em sistemas de manejo do solo deficitários em água, a queda de estruturas reprodutivas passa a ser grande, ao passo que em condições satisfatórias de água no solo, a planta normalmente apresenta maior retenção dessas estruturas.

\section{Abscisão de estruturas reprodutivas}

Na Figura 5, observa-se que não houve diferença significativa $(\mathrm{p}>0,05)$ entre os níveis de água disponível no solo para a abscisão de estruturas reprodutivas do algodoeiro. Este resultado indica que se trata de uma relação proporcional e que esta se mantém independentemente da disponibilidade de água no solo, ou seja, proporcionalmente a fase posterior depende da anterior. De acordo com a análise desses dados verifica-se, ainda, que, apesar dos tratamentos terem influenciado quantitativamente a emissão e abscisão das estruturas reprodutivas, como foi verificado na Figura 3, a relação entre essas se mantém, assim como a abscisão, quando expressa em termos de porcentagem (Fig. 5).

Considerando-se as três principais fases do desenvolvimento reprodutivo do algodoeiro (Fig. 5), botões florais para flores (A), flores para maçãs (E) e maçãs para capulhos (F) constatou-se maior abscisão, em torno de $38 \%$, no florescimento, ou seja, $38 \%$ das flores sofreram abscisão antes de passarem à fase de maçãs (E) o que deve estar associado à deficiência hídrica, uma vez que, do início ao término da floração, é o período mais crítico à falta de água (Millar, 1976; Luz et al., 1997); entretanto, deve-se considerar que, embora a deficiência hídrica severa eleve a abscisão de frutos, os efeitos do estado hídrico da planta na retenção de frutos não são únicos, como chamam a atenção Guinn \& Mauney (1984a).

\section{CONCLUSÕES}

1. O crescimento vegetativo, a quantidade e a evolução de estruturas reprodutivas, aumentaram significativamente com os níveis de $\mathrm{AD}$ no solo, até $60 \%$, sendo a menor quantidade de botões florais, flores, maçãs e capulhos por planta observada no tratamento com $20 \%$ da $\mathrm{AD}$ e a maior, no tratamento com o nível de $60 \%$ da $\mathrm{AD}$.

2. O número de botões florais, flores, maçãs e capulhos no algodoeiro reduziu significativamente com o aumento do estresse hídrico, porém a proporcionalidade entre a taxa de emissão/abscisão é mantida, independente do nível de estresse aplicado.

\section{LITERATURA CITADA}

Blake, G.R. Particle density. In: Black, C.A. (ed.) Methods of soil analysis. Madison: American Society of Agronomy, 1965a. p.374-390. Agronomy, 9

Blake, G.R. Bulk density. In: Black, C.A. (ed.) Methods of soil analysis. Madison: American Society of Agronomy, 1965b. p.371-373. Agronomy, 9

Day, P.R. Particle fractionation and particle size analysis. In: Black, C.A. (ed.) Methods of soil analysis. Madison: American Society of Agronomy, 1965. p.545-567. 
Diniz, J.A. Sistemas de manejo do solo e níveis de nitrogênio: efeito sobre o estabelecimento, crescimento, desenvolvimento e rendimento do algodoeiro herbáceo. Areia: CCA/ UFPB. 1996. 98p. Dissertação Mestrado

Doorenbos, J.; Kassam, A.H. Efeito da água no rendimento da cultura. Campina Grande: UFPB. 1994. 306p. Estudos FAO: Irrigação e Drenagem, 33

Espínola Sobrinho, J.; Maia Neto, J.M. Necessidades hídricas para o algodoeiro na região Oeste do Rio Grande do Norte. In: Congresso Nacional de Irrigação e Drenagem, 9. 1991. Natal, RN. Anais... Fortaleza: ABID, 1992. v.2, p.923-945.

Forsythe, W.M. Física de suelos: Manual de laboratorio. San José: Instituto Interamericano de Ciências Agrícolas, 1975, 212p.

Gomes, F.P. Curso de estatística experimental. $8^{\mathrm{a}}$ ed. São Paulo: Nobel. 1985. 466p.

Grimes, D.W.; Dickens, W.L.; Yamada, H. Early season water management for cotton. Agronomy Journal, Madison, v.70, p.1009-1012, 1978.

Guinn, G. Hormonal relations in flowering, fruiting and cutout. In: Beltwide Cotton Production Research Conference, 1979. Phoenix, Arizona. Proceeding... Memphis, TN: National Cotton Council, 1979. p.265-276.

Guinn, G.; Mauney, J.R. Fruting in of cotton: I. Effects of moisture status on flowering. Agronomy Journal, Madison, v.76, p.9094, 1984a.

Guinn, G.; Mauney, J.R. Fruting in of cotton: II. Effects of plant moisture status and active boll load on boll retention. Agronomy Journal, Madison, v.76, p.94-98, 1984b.

Hearn, A.B. Water relationships in cotton. Outlook on Agriculture, London, v.10, p.159-166, 1980.

Hsiao, T.C. Plant response to water stress. Annual Review of Plant Physiology, Palo Alto, v.24, p.519-570, 1973.

Jackson B.S.; Arkin G.F. Fruit growth in a cotton simulation model. In: Beltwide Cotton Production Research Conference, 1982. Phoenix, Arizona. Proceeding... Memphis, TN: National Cotton Council, 1982, p.61-64.

Kittock, D.L. Pima and upland cotton response to irrigation management. Agronomy Journal, Madison, v.71, p.617-619, 1979.

Lima, J.S. Bioindicação, biomonitoramento: Aspectos bioquímicos e morfológicos. http://www.ietec.com.br. 2001.

Luz, M.J. da S. e; Bezerra, J.R.C.; Barreto, A.N.; Santos, J.W. dos; Amorim Neto, M. da S. Efeito da deficiência hídrica sobre o rendimento e a qualidade da fibra do algodoeiro. Revista de Oleaginosas e Fibrosas, Campina Grande, v.1, n.1, p.125-133, 1997.

Mauney, J.R. Production of fruiting points. Stewart, J.M. (ed.) Cotton physiology-A treatise: Section I. Flowering, Fruiting and Cutout. In: Beltwide Cotton Production Research Conference, 1979. Phoenix, Arizona. Proceeding... Memphis, TN: National Cotton Council. 1979. p.256-261.

McMichael, B.L.; Jordan, W.R.; Powell, R.D. An effect of water stress on ethylene production by intact cotton petioles. Plant Physiology, Baltimore-Maryland, v.49, p.658-660, 1973.
Millar, A.A. Respuesta de los cultivos al deficit de agua como información básica para el manejo del riego. Petrolina: EMBRAPA-CPATSA. 1976.62p.

Nápoles, F.A. de M.; Amorin Neto, M. da S.; Bezerra, J.R.C.; Silva, L.C.; Luz, M.J. da S. e; Neto, J.D. Efeito da época da supressão da irrigação sobre parâmetros morfo-fisiológicos do algodoeiro. In: Congresso Brasileiro do Algodão, 2, 1999, Ribeirão Preto. Anais... Campina Grande: EMBRAPA-CNPA, 1999, p.507-512.

Nóbrega, J.C.A. Estudo comparativo de propriedades físicas de um Latossolo Vermelho-Amarelo, com ênfase na detecção de camadas compactadas ou adensadas. Areia: CCA/UFPB. 1996, 67p. Monografia

Oosterhuis, D.M. Growth and development of a cotton plant. Faytteville: University of Arkansas Cooperative Extension Service. 1992. 24p. MP332-4M-9-92R

Orgaz, F.; Bonachela, S.; Mateos, L.; Fereres. E. Desarrollo fenológico y producción de cultivares de algodon en el valle del Guadalquivir bajo diversos regimenes de riego. Investigacion Agraria: Produccion y proteccion vegetales, Madrid, Espãna, v.6, n.1, 1991.

Orgaz, F; Mateos, L.; Fereres, E. Season length and cultivar determine the optimum evapotranspiration deficit in cotton. Agronomy Journal, Madison, v.84, n.4, p.700-706, 1992.

Pereira, M. do N.B.; Azevedo, N.C. de; Fernandes, P.D.; Amorim Neto, M. da S. Crescimento e desenvolvimento de duas cultivares de algodoeiro herbáceo em baixos níveis de umidade no solo, em casa de vegetação. Revista Brasileira de Engenharia Agrícola e Ambiental, Campina Grande, v.1, p.1-7, 1997.

Raij, B. van.; Cantarella, H.; Zullo, M.A.T. O método tampão SMP para determinação da necessidade de calagem de solos do Estado de São Paulo. Bragantia, Campinas, v.38, n.7, p.57-69, 1979.

Rosolem, C.A. Ecofisiologia e manejo cultural do algodoeiro: Ecofisiologia do algodoeiro. In: Mato Grosso, Liderança e competitividade. Rondonópolis: Fundação MT, Campina Grande: EMBRAPA/CNPA, 1999. 182p. cap.4, p.49-69. Boletim, 3

Sousa, J.G. de; Beltrão, N.E. de M. Efeitos do encharcamento do solo na fisiologia do algodoeiro (Gossypium hirsutum L. r. Latifolium Hutch) em condições de casa de vegetação. In: Congresso Brasileiro do Algodão, 1, 1997, Fortaleza. Anais... Campina Grande: EMBRAPA/CNPA, 1997. p.311-313.

Steel, R.G.D.; Torrie, J.H. Principles and procedures of statistics: Biometrical approach. New York: McGraw-Hill Book, 1980.481p.

Tedesco, M.J.; Volkweiss, S.; Bohnen, H. Análises de solo, plantas e outros materiais. Porto Alegre: UFRGS, Faculdade de Agronomia. 1985. 188p.

Wright, G.C.; Nageswara Rao, R.C. Groundnut water relations. In. Smartt, J. The groundnut crop: Scientific basis for improvement. London: Chapman \& Hall, 1994. p.281-335. 